\title{
LA OBRA CINEMATOGRÁFICA DE SHADI ABDEL SALAM: EL CINE COMO HERRAMIENTA DE RECUPERACIÓN DEL PASADO FARAÓNICO ${ }^{1}$
}

\author{
Shadi Abdel Salam's Cinematographic Works: Cinema As a Tool to Recover the Pharaonic Past
}

SAmuel Montes Ibars ${ }^{\mathrm{a}}$

Universidad de Alcalá

DOI: 10.15366/secuencias2020.51.002

\begin{abstract}
RESUMEN
Este artículo tiene como objetivo principal el análisis de la obra cinematográfica de Shadi Abdel Salam. Se trata de uno de los directores árabes de mayor singularidad, aunque su obra completa es prácticamente desconocida para la historiografía occidental. Mediante la recopilación bibliográfica de información referente a su trayectoria biográfica, de diversos textos que examinan sus películas, así como del visionado de su producción cinematográfica, se pone en valor la figura de un director de cine caracterizado por una gran profundidad intelectual y una marcada intencionalidad artística.

A través de sus obras, ambientadas en acontecimientos históricos de distintas épocas, transmite su personalidad artística y su pensamiento en torno al cine. Para Abdel Salam, las imágenes en sí mismas constituyen un elemento artístico, siendo el componente visual lo más importante. Además, concibe el cine como una herramienta de recuperación de un pasado que se encuentra fuera de la memoria histórica, un medio por el cual pueden abrirse profundos debates en el seno de la sociedad egipcia. Abdel Salam ambienta sus películas, bien en el antiguo Egipto, bien en otras etapas históricas, pero con este pasado muy presente, con el objetivo de recuperar el legado sociocultural del pasado faraónico. Este hecho le confiere un carácter único y excepcional, no solo dentro de la cinematografía egipcia, sino también en el seno de la producción árabe.
\end{abstract}

Palabras clave: cine árabe, cine histórico, educación, Egipto faraónico, recuperación histórica, memoria histórica, panarabismo, patrimonio cultural

\section{ABSTRACT}

This article aims to carry out an analysis of Shadi Abdel Salam's cinematographic work. He is one of the most singular Arab directors, although his complete work is practically unknown to Western historiography. Through the bibliographical examination of his personal career and the analysis of works dealing with his films, as well as the viewing his films, it is possible to reevaluate the figure of this film director, characterized by a great intellectual depth and marked artistic intentionality.

Across his works, focused on historical milestones from different eras, he transmits his artistic personality and his thoughts about cinema. For Abdel Salam, the images themselves constitute an artistic element, the most significant one being the visual component. Moreover, he conceives cinema as a tool for the recovery of a past that remains outside the historical memory,

[1] Este texto es el ganador del III Premio Alberto Elena de Investigación en Cines Periféricos, convocado por el grupo de investigación TECMERIN (Universidad Carlos III de Madrid) y Secuencias. Revista de historia del cine. Fue fallado el 12 de diciembre de 2019 por el jurado integrado por Gérard Imbert (TECMERIN), Xose Prieto Souto (TECMERIN) y Sonia Dueñas (TECMERIN). El premio incluye la publicación del texto en Secuencias. a means by which deep discussions can flourish within Egyptian society. Abdel Salam sets his movies either in ancient Egypt or in other historical eras, but with this past very present, with the aim of recovering the socio-cultural legacy of the pharaonic past. This fact conferred him a unique and exceptional character, not only within Egyptian cinematography, but also among Arab productions.

Keywords: Arabic cinema, historical cinema, education, Pharaonic Egypt, historical memory, Pan-Arabism, cultural heritage, historical recovery

[a] Samuel Montes Ibars es Doctor en Historia del Arte por la Universidad de Salamanca, especializado en Historia del cine español entre 1925 y 1950. Actualmente, es investigador posdoctoral en la Universidad de Alcalá y pertenece al proyecto «Midle Kingdom Theban Project». Posee dos líneas de investigación: el estudio de la reproducción en formato facsímil de pinturas funerarias en Deir el-Bahari (Luxor) y el cine egipcio ambientado en la época faraónica. Obtuvo la beca BBK-Museo de Bellas Artes de Bilbao en 2018 y realizó una investigación sobre la Cinemateca de Bilbao y la crítica de cine en Euskadi. E-mail: samumont@usal.es 
«La momia tiene un tono extremadamente inusual: majestuoso, poético, con una poderosa comprensión del tiempo y la tristeza que ello conlleva» ${ }^{2}$.

Martin Scorsese

\section{Introducción}

El trabajo cinematográfico de Shadi Abdel Salam se desarrolló entre 1957 y 1982, coincidiendo con los regímenes egipcios de Gamal Abdel Nasser (1954 - 1970) y de Mohamed Anwar al Sadat (1970 - 1981) ${ }^{3}$. Sin embargo, sus proyectos son, en gran parte, consecuencia de los cambios políticos, económicos y sociales que se produjeron en Egipto tras la Revolución de los Oficiales Libres en 1952 y la posterior subida al poder de Nasser en 1954. Las medidas adoptadas por el nuevo régimen afectaron de manera decisiva a la industria cinematográfica del país.

La llegada al poder de Nasser trajo consigo una nueva configuración sociopolítica marcada por el socialismo y el nacionalismo panarabista. Este nuevo régimen poscolonial estaba intentando construir un Estado cuya identidad nacional fuera «auténtica», independiente de la influencia colonial. Esta circunstancia tuvo su reflejo en la producción de géneros cinematográficos inexistentes en Egipto o con escasa representación hasta ese momento. Este fue el caso del cine histórico, a través del cual se recuperaban hitos gloriosos o personajes heroicos, mayormente relacionados con etapas relevantes de la historia del islam medieval. Durante el mandato de Nasser, se produjeron más de una decena de films históricos. En ellos se trataba de reflejar la represión que sufrieron los primeros musulmanes, por un lado, y de legitimar las ideas políticas del panarabismo, especialmente la independencia respecto de las potencias coloniales, por otro ${ }^{4}$. Entre las obras más destacadas pueden citarse iOh, Islam! (Wa Islamah, Andrew Marton, 1961) y Saladino (al-Nasir Salah al-Din, Youssef Chahine, 1963).

Además, en 1963 se produjo un proceso de nacionalización que afectó de forma directa a la industria cinematográfica. La mayoría de los films producidos en esta época fueron financiados por el Estado a través de la Organización General del Cine. Cabe recordar que, hasta ese momento, la producción de cine se hallaba en manos privadas y, por lo tanto, se caracterizaba por el cine de género y entretenimiento ${ }^{5}$.

Nasser murió de forma repentina el 28 de septiembre de 1970, siendo sustituido por Anwar al Sadat. Sus políticas, denominadas Infitah (apertura), tenían como objetivo ir revirtiendo paulatinamente las medidas socialistas, así como establecer mayor libertad económica. Este hecho favoreció la vuelta del capital privado en todos los sectores económicos del país, incluido el cine.

En este contexto sociopolítico desarrolló su carrera cinematográfica el realizador Shadi Abdel Salam, quien, a través de un modelo de cine histórico y con una clara vocación artística, intentará sentar las bases de un lenguaje audiovisual nacional propio, perfectamente configurado y reconocible.

[2] Martin Scorsese, World Cinema Project, 2009. Disponible en: <http://www.filmfoundation.org/world-cinema $>$ (18/09/2019). (La traducción es nuestra).

[3] Por motivos de extensión, se remite a dos obras de referencia para consultar la Historia del cine egipcio: Alberto Elena, «Elementos para una historia del cine en el mundo árabe», en Los cines periféricos: África, Oriente Medio, India (Barcelona, Paidós, 1999), pp. 189-243 y Viola Shafik, «Egyptian Cinema», en Oliver Leaman (ed.), Companion Encyclopedia of Middle Eastern and North African Film (London; New York, Routledge, 2001), pp. 23-130.

[4] Un ejemplo es Yamila, la argelina (Djamilah, Youssef Chahine, 1958), que narra de forma épica el proceso de independencia de Argelia.

[5] Véase Alberto Elena, «Elementos para una historia del cine en el mundo árabe», p. 189-243. 


\section{El pasado faraónico en la cinematografía egipcia}

A pesar del creciente interés por la realización de cine histórico durante el nasserismo, la presencia del pasado faraónico en las producciones egipcias brilla por su ausencia. Exceptuando las obras de Abdel Salam, no existen producciones egipcias ambientadas en el antiguo Egipto o que reflexionen sobre la identidad cultural heredada de la época de los faraones. Evidentemente, la ausencia de referencias artísticas del antiguo Egipto en el cine autóctono responde a varias causas, algunas de las cuales van más allá de la mera preferencia estética de los espectadores.

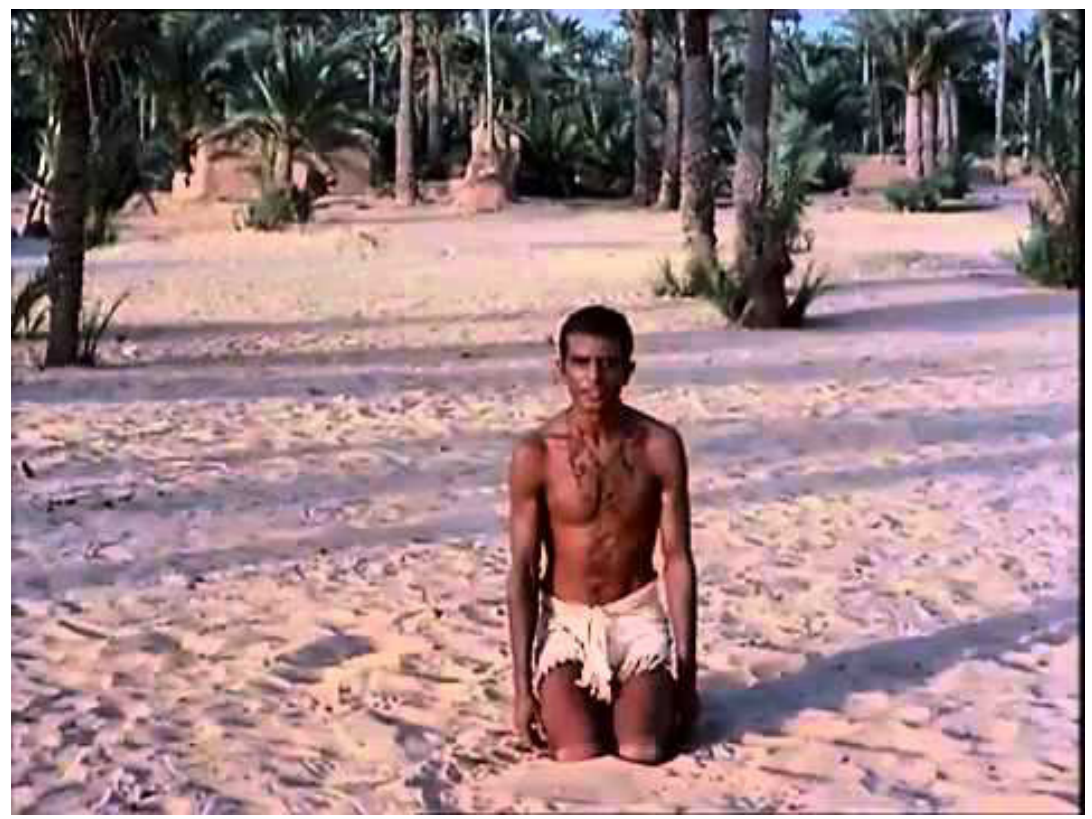

Fotograma de El campesino elocuente (al-Falah al-Fasih, Shadi Abdel Salam, 1975).

Ante todo, ha de tenerse en cuenta la percepción que los egipcios tenían y tienen de ese pasado. Hablando siempre de manera generalizada, con los riesgos que ello entraña, se percibe que la época faraónica está relegada a un segundo plano entre la sociedad egipcia, pues tienden a considerarlo un elemento ajeno a la configuración moral y política que durante siglos ha establecido el islam. Se pueden citar dos hechos que ilustran la posición secundaria del pasado preislámico. El primero de ellos, relacionado con la educación, es que los libros de texto y de historia de Egipto inician el relato histórico con la conquista musulmana del año 642 bajo el califato de Omar. El segundo ejemplo está ligado a la gestión patrimonial del pasado faraónico. A excepción de unos cuantos expertos y algunas personas interesadas en el tema, el antiguo Egipto y sus colosales monumentos se perciben como una fuente de ingresos que se 
canalizan a través del turismo y de las concesiones arqueológicas a equipos de investigación extranjeros. Siguiendo esta línea, no pasan desapercibidas las graves deficiencias que ha estado sufriendo la instalación museográfica del Museo Egipcio de El Cairo. Para paliarlas, ha sido necesaria una financiación conjunta de más de tres millones de euros a través de un consorcio de centros europeos, entre los que estaban el Museo Británico o el Museo del Louvre. Eso sí, es justo señalar que esta situación se ha ido revirtiendo con el paso del tiempo, tal y como demuestra dicho proyecto de renovación museológica ${ }^{6}$.

\section{La obra cinematográfica de Shadi Abdel Salam}

\subsection{Apuntes biográficos}

Shadi Abdel Salam nació en la ciudad de Alejandría el 15 de marzo de 1930, en el seno de una familia liberal. Su padre ejercía la abogacía en Alejandría, así que puede deducirse que Abdel Salam gozó de acceso a una formación cultural de calidad. Durante su infancia y adolescencia alternó estancias entre Alejandría y Minya, una región rural situada en el Alto Egipto y estrechamente vinculada con el pasado faraónico. Esta dicotomía entre los modos vida de la ciudad y del campo, así como la presencia de vestigios monumentales del antiguo Egipto en su residencia rural, marcarán profundamente el pensamiento y la obra de Abdel Salam. A los diecinueve años viajó a Londres para estudiar Arte Dramático, pero no mostró el talento suficiente y regresó a Egipto. De vuelta en su país natal estudió Arquitectura y se graduó en 1954 en la Escuela de Bellas Artes de El Cairo.

Sus primeros contactos con la industria cinematográfica se produjeron en 1957, año en el que comenzó a trabajar como ayudante del diseñador artístico Ramses Wasif. Continuó su carrera en Egipto, donde participó en los diseños de producciones nacionales históricas tan relevantes como iOh, Islam! (Andrew Marton, 1961) y Saladino (Youssef Chahine, 1963).

En 1963 Shadi Abdel Salam llevó a cabo tres colaboraciones en producciones extranjeras de las que obtuvo una serie de contactos que facilitaron su acceso a la dirección de películas y también diversas influencias que son rastreables en sus obras. Su primer trabajo en una producción foránea fue como diseñador en el film Cleopatra (Joseph Mankiewicz, 1963). Poco después, en 1965, se encargaría de diseñar el vestuario de Faraón (Pharaoh, Jerzy Kawalerowicz, 1965), una producción polaca que generalmente es reconocida por los egiptólogos como una de las películas que mejor reproducen la cultura y sociedad del antiguo Egipto ${ }^{7}$. Parece razonable pensar que Abdel Salam poseía un conocimiento profundo de esta civilización y una gran capacidad creativa para trasladar la iconografía faraónica a la imagen cinematográfica, tal y como demuestran los bocetos, dibujos y recreaciones escultóricas y arquitectónicas que llevó a cabo para sus proyectos fílmicos. En este contexto, aparece la figura de Roberto Rossellini en la carrera de Abdel Salam. El di-
[6] Sol García Moreno, «Un consorcio de centros europeos como el Louvre o el British renovará el Museo Egipcio de El Cairo" (ARS Magazine, 2019). Disponible en: <https://arsmagazine.com/un-consorciode-centros-europeos-como-ellouvre-o-el-british-renovarael-museo-egipcio-de-el-cairo/> (16/05/2019)

[7] Raúl Sánchez Casado, «Ritual egipcio y cine: la representación cinematográfica de la práctica cultural del antiguo Egipto» (Cine e Historia [s]. Maneras de relatar el pasado con imágenes, París, 2015), p. 121: «Pese a ello, contamos con honrosas excepciones con una recreación magnífica, cuyo paradigma es, sin duda, Faraón (Jeryz Kawalerowicz 1966)». 
[8] Shadi Abdel Salam, «Entrevista» (Gomhuria Magazine, 16 de diciembre de1969). Disponible en: <http://www.luxorafricanfilmfestival.com/en/ PastEditions/2014/TributeDedication/Shadi\%20Abdel\%20 Salam>, (01/03/2020). (La traducción es nuestra). rector y productor italiano se hallaba inmerso desde 1963 en el rodaje de una serie de documentales para la RAI-Italia titulada La lucha del hombre por la supervivencia (La lotta dell'uomo per la sua sopravvivenza). Se trata de una producción de Orizzonte, empresa fundada por Rossellini, en la que participaron la RAI (Roma), Copro Films (El Cairo), Logos Films (París) y Romania Film (Bucarest). Copro Film, una firma cinematográfica fundada y afincada en Egipto, se caracterizó por llevar a cabo coproducciones internacionales, colaborando especialmente con empresas italianas. Así pues, todo parece indicar que Abdel Salam pasó a formar parte del equipo de trabajo de Rossellini a través de esta productora cairota. La serie se compone de doce capítulos que fueron dirigidos por Renzo Rossellini, hijo de Roberto, y Marcella De Marchis. El segundo capítulo se titula La civilización que nació de un río ( $L a$ civilità che nacque da un fiume) y narra el desarrollo de la civilización egipcia en el valle del Nilo, incidiendo en la vida cotidiana del Egipto faraónico con sus cultos, castas, formas de producción y dominación. Shadi Abdel Salam colaboró en este episodio en la confección de los decorados y diseños junto a Marcella De Marchis, directora de vestuario de la serie documental. Esta colaboración resulta fundamental en la carrera del realizador alejandrino, pues Rossellini apoyó de forma decisiva la producción de su primer largometraje: La momia (al-Mumya).

En 1968 Shadi Abdel Salam, espoleado por Roberto Rossellini, se lanzó a la dirección de películas con un proyecto titulado La momia. Abdel Salam siempre tuvo en mente la idea de dirigir películas, de trasladar su trabajo como diseñador al arte cinematográfico: «Quería que mis dibujos se moviesen y las imágenes solo se mueven en el cine» ${ }^{8}$. Poco después de llevar a cabo $L a$ momia, su único largometraje, dirigió en 1970 El campesino elocuente (alFalah al-Fasih), un cortometraje basado en un relato homónimo del Reino Medio egipcio (circa. 1900 a. C.). Durante las décadas de los setenta y ochenta, Abdel Salam realizó documentales. El primero de ellos, Horizontes (Afaq, 1973), muestra la vida cotidiana en el Egipto contemporáneo a través de sus costumbres y manifestaciones artísticas. Por su parte, Ejércitos del sol (Jiyush al-Shams ) se estrenó en 1975 y narra las experiencias en primera persona de los soldados durante la guerra de Yom Kipur. Ya en los ochenta Abdel Salam filmó tres documentales en los que reflexiona sobre el antiguo Egipto: El trono de oro de Tutankamón (Korssy Tout Ankh Amun Al Zahaby, 1982), Detrás de las pirámides (al-Ahram Wa Ma Qabliha, 1984) y A propósito de Ramsés II ('An Ramsis al-Thani, 1986). En estas tres producciones se ponen de manifiesto la relevancia histórica del pasado faraónico, el valor de su cultura material y su importancia como elemento fundamental de la identidad egipcia. En su último proyecto, Akhenatón (Ikhnâtoun ), trabajó durante diez años, pero quedó inconcluso por la falta de interés del gobierno egipcio y de los productores y, sobre todo, por la inexistencia de fuentes de financiación. Se trataba de una producción muy ambiciosa y de gran envergadura sobre la vida del faraón Akhenatón. 
Aparte de sus labores como diseñador de vestuario, escenógrafo, guionista y director, Shadi Abdel Salam impartió clases en el Instituto Superior de Cine de Egipto entre 1963 y 1969, en los Departamentos de Decoración, Vestuario y Dirección de Cine. En 1968 fue nombrado jefe del Departamento de Cine Experimental, una sección dependiente de la Organización General del Cine desde la que intentó promover una mayor atracción visual en la dirección de los films. Su influencia fue decisiva para dos notables escenógrafos egipcios: Salah Marei y Onsi Abou Seif 9

Shadi Abdel Salam falleció el 8 de octubre de 1982 en El Cairo a los cincuenta y seis años de edad a causa de un cáncer, poniendo fin a una de las trayectorias cinematográficas más singulares de la Historia del cine egipcio.

\subsection{Análisis filmográfico}

3.2.1 La momia. Un largometraje singular

Se trata del primer y único largometraje de ficción realizado por Abdel Salam, un hecho muy sorprendente si tenemos en cuenta el alto grado de sofisticación técnico y artístico que alcanza este film. En palabras de Viola Shafik, «esta película se considera la obra maestra de la cinematografía egipcia. En ella se aborda

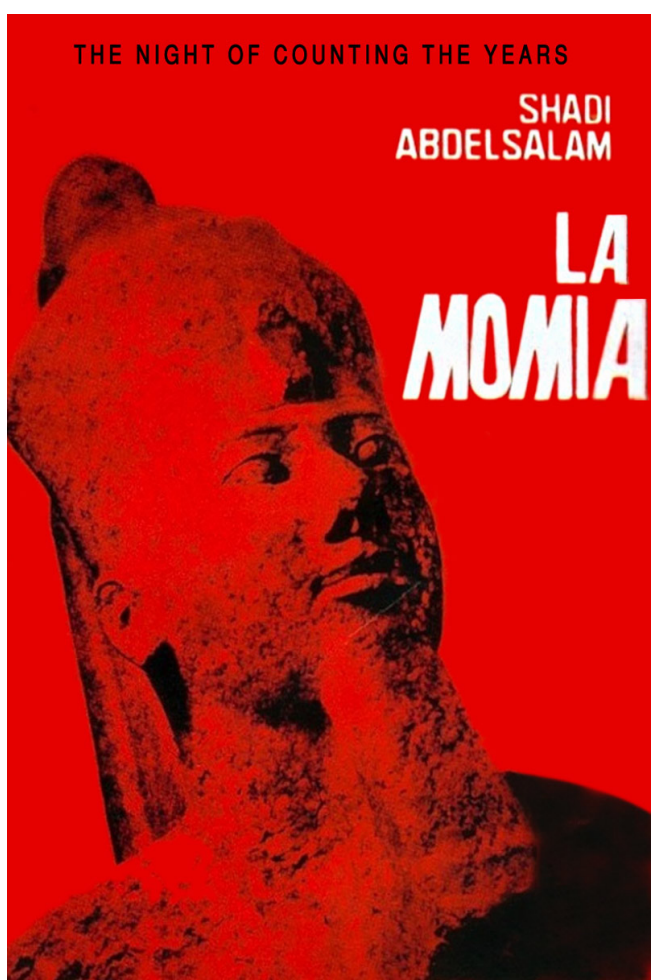

Cartel de La momia (al-Mumyas, Shadi Abdel Salam, 1969). la búsqueda de la identidad cultural y una interpretación adecuada de la historia» ${ }^{10}$. Nos encontramos ante una obra cinematográfica de especial singularidad debido al género al que pertenece, la temática que aborda, las características técnicas, la intencionalidad artística y las reflexiones filosóficas que plantea.

Abdel Salam apostó por llevar a cabo una recreación histórica en su opera prima. La elección del género histórico resultaba arriesgada, ya que su tratamiento en la industria cinematográfica egipcia había sido más bien escaso. No obstante, este tipo de producciones estaban experimentando un considerable impulso des-
[9] «Uno de los legados más determinantes fue la influencia que tuvo sobre dos escenógrafos, Salah Marei y Abu Saif, cuyos trabajos elevaron considerablemente la calidad del cine egipcio». Viola Shafik, «Egyptian Cinema», p. 89. (La traducción es nuestra)

[10] Viola Shafik, «Egyptian Cinema». (La traducción es nuestra). 
[11] Ana Torres García, «Cine, historia e identidad nacional: La Momia de Šādī 'Abd alSalām» (Miscelánea de estudios árabes y hebraicos. Sección Árabe-Islam, 51, 2002), p. 320 .

[12] Shadi Abdel Salam, «Entrevista». de instancias gubernamentales durante el régimen de Nasser, pues se estaba utilizando la narración de acontecimientos del pasado como herramienta de legitimación política. Simplemente atendiendo a su ambientación, salta a la vista la peculiaridad de este film. De hecho, hasta ese momento los cineastas egipcios no habían trabajado sobre el periodo preislámico de Egipto. Sin embargo, el realizador alejandrino nos lleva a las entrañas de una tribu rural que vive prácticamente aislada en las montañas, cerca del complejo funerario de Deir el-Bahari, en un momento en el que se están descubriendo multitud de enterramientos de la época faraónica. Es más, su inspiración directa fue el descubrimiento de un conjunto de momias en 1881 en Deir el-Bahari, entre las que se encontraban las de los faraones de diferentes dinastías ${ }^{11}$.

A pesar de las dificultades que afrontaba Abdel Salam al plantear una película de género histórico relacionada con el antiguo Egipto, contó con el inestimable apoyo de Roberto Rossellini. Como él mismo comentaba en una entrevista que concedió en 1969, Rossellini conocía su trabajo a través de sus diseños en Faraón ${ }^{12}$. Cuando el italiano se encontraba en Egipto rodando el segundo capítulo de su serie documental La lucha del hombre por la supervivencia, en cuyos diseños participaba Abdel Salam, leyó el guion de La momia y decidió apoyarle en su realización. Sin embargo, tuvo que abandonar el país en junio de 1967 debido al estallido de la Guerra de los Seis Días. Este hecho no impidió que siguiese respaldando decididamente el proyecto de La momia y contribuyó, por una parte, a la búsqueda de financiación convenciendo a Tharwat Okasha, a la sazón Ministro de Cultura egipcio, de la necesidad de llevar a cabo esta película y, por otra, prestando su apoyo en tareas de posproducción desde Italia. Este último hecho provocó reticencias en ciertos sectores de la Organización General del Cine, que acusaron al director alejandrino de derrochar dinero en estudios extranjeros. Dicha acusación, negada rotundamente por el propio Abdel Salam, no parece muy consistente si tenemos en cuenta su trayectoria artística e intelectual. Prácticamente toda su obra se centra en la definición de la identidad egipcia, con una voluntad absoluta de emplear todos los medios logísticos nacionales que fueran posibles.

La historia narra el complejo dilema ético al que ha de enfrentarse Wanis (Ahmed Marei), el hijo menor del jefe de la tribu Hurabat, cuyos miembros se dedican aparentemente al pastoreo desde hace quinientos años. A la muerte de su padre, tanto Wanis como su hermano mayor (Ahmad Hegazi) son llamados por dos líderes ancianos (Abdelmonen Aboulfoutouh y Abdelazim Abdelhack) para confesarles que, con el objetivo de asegurar la subsistencia de la tribu, llevan cientos de años saqueando los tesoros de los sarcófagos y comercializándolos en el mercado negro. De manera simultánea, la venta ilegal de un papiro de la Dinastía XI con el nombre de la Reina Nedjmet activa las alarmas en el Museo Egipcio de El Cairo. Sus responsables deciden enviar una expedición liderada por Ahmed Kamal (Mohamed Khairi) para descubrir el origen de este objeto. El hermano mayor de Wanis, que rechaza completamente la profanación de los sarcófagos, es asesinado por los ancianos de la tribu. A medida que 
avanza la narración, afloran las contradicciones morales de Wanis. Si bien se opone al saqueo sistemático de los enterramientos, es consciente de que su tribu necesita vender objetos si quiere sobrevivir. Finalmente, Wanis comprende que, a pesar de ser una civilización lejana en el tiempo, el Egipto faraónico forma parte del legado cultural de su pueblo y revela el lugar donde se encuentran los sarcófagos. Para sorpresa de Kamal, descubren que hay unos cuarenta sarcófagos de varias Dinastías, desde la XIX a la XXI (Amenhotep I, Seti I, etc.). A pesar del peligro de ser atacados por los Hurabat, optan por trasladarlos en barco hasta El Cairo. Mientras se alejan a través del Nilo, Wanis los observa con gestos contradictorios de alivio y dolor.

Como señala el egiptólogo Miguel Ángel Molinero «La momia resulta mucho más compleja que la simple querella por un botín arqueológico» ${ }^{13}$. Esta película, más que ofrecer respuestas certeras, plantea interrogantes a los espectadores acerca del pasado faraónico y su influencia sobre la identidad nacional egipcia. Abdel Salam busca sacudir la conciencia de sus compatriotas, generar en ellos una reflexión sobre su pasado para que busquen en su propia configuración moral el legado cultural del antiguo Egipto. El director expone la necesidad de recuperar del olvido ese pasado, salvaguardarlo y difundirlo como parte consustancial de la identidad egipcia. La idea de otorgarle al antiguo Egipto un papel fundamental en la Historia es uno de los aspectos más determinantes del film por sus implicaciones ideológicas. Abdel Salam muestra el legado faraónico como un hito fundacional del país, una tesis defendida por ciertos intelectuales y políticos. Uno de los más destacados fue Taha Hussein, rector de la Universidad de El Cairo, miembro de la Academia de la Lengua Árabe y Ministro de Educación, que defendió firmemente la importancia del pasado preislámico. Si bien es muy complicado demostrar que estuviesen en contacto directo, parece bastante razonable pensar que Abdel Salam se viera influido por su pensamiento. En un contexto sociopolítico en el que se trataba de imponer el nacionalismo árabe, estas ideas adoptaban un carácter anticolonialista, pues se consideraba que a las potencias coloniales les interesaba que cualquier hito o personaje histórico que fomentara de alguna manera la identidad egipcia cayese en olvido, incluida la etapa preislámica. La momia sería, en parte, una transposición audiovisual de estas ideas, un medio de difusión de conceptos ideológicos nacionalistas a través de una ficción muy realista.

El film ofrece multitud de recursos técnicos que entroncan directamente con el cine neorrealista italiano, que Abdel Salam conoció de primera mano a través de Rossellini. El hecho de que las labores de postproducción se llevaran a cabo en Italia, bajo la supervisión y el apoyo de Rossellini, otorgan influencias neorrealistas a la obra. En este sentido, los aspectos más fácilmente identificables los encontramos en esa voluntad clara de reflejar realidades sociales, en este caso del mundo rural egipcio, en la ambientación en entornos naturales y exteriores, la iluminación eminentemente natural, la utilización de lenguajes autóctonos (árabe clásico) y en el verismo absoluto que desprenden los actores a través de su caracterización.
[13] Miguel Ángel Molinero Polo, «La momia de Shadi Abdel-Salam y la arqueología colonial», en Miguel Ángel Molinero y Domingo Sola (coord.), Arte y sociedad del antiguo Egipto (Madrid, Zugarto, 2000), p. 278. 
Quizá uno de los aspectos que destaca de manera particular en esta película es la utilización de metáforas cinematográficas que buscan ahondar en la necesidad de mantener vivo el legado faraónico, por un lado, y difuminar las barreras entre el antiguo Egipto y el contemporáneo, por otro.

El film arranca con un primer plano de una máscara funeraria fragmentada sobre la que se proyectan los títulos de crédito. Esta imagen alude a la pérdida de la cultura faraónica, no solo desde un punto de vista material, sino desde el punto de vista espiritual. No debemos olvidar que, para los antiguos egipcios, la reproducción de una persona significaba que parte de su alma, el Ka, se ubicaba ahí, por lo que su destrucción equivale a su pérdida. Este mensaje lo refuerza Gaston Maspero (Gaby Karraz), el egiptólogo que dirige el Museo Egipcio de El Cairo, recitando un fragmento de El libro de los muertos que concluye con una referencia a la pérdida del nombre o, lo que es lo mismo, a la pérdida de la propia identidad.

Otro recurso que utiliza Abdel Salam es establecer una relación directa entre Wanis y el antiguo Egipto. Para ello es fundamental la extraordinaria interpretación de Ahmed Marei, capaz de llevar el hieratismo y la contención física hasta límites que desconciertan al espectador. Su rostro se presenta en planos frontales, emulando las características básicas del arte plástico egipcio. En una escena marcada por un tenso cruce de miradas entre Wanis y Kamal, este último comenta con su asistente Badawi (Ahmad Anan) que Wanis «tiene una extraña mirada, como una estatua que ha tomado vida».

En su voluntad por diluir la diferenciación entre el pasado y el presente de Egipto, Abdel Salam sitúa gran parte de las escenas en exteriores, de tal forma que el marco arquitectónico donde se producen esos acontecimientos relativamente actuales son los monumentos de época faraónica. La película muestra constantes contraposiciones entre los amplios planos del paisaje y de los restos monumentales frente a primerísimos planos de los rostros de los protagonistas. Esa misma confrontación existe entre el rostro de Wanis y las caras de los sarcófagos. Todos estos recursos visuales tratan de remarcar las
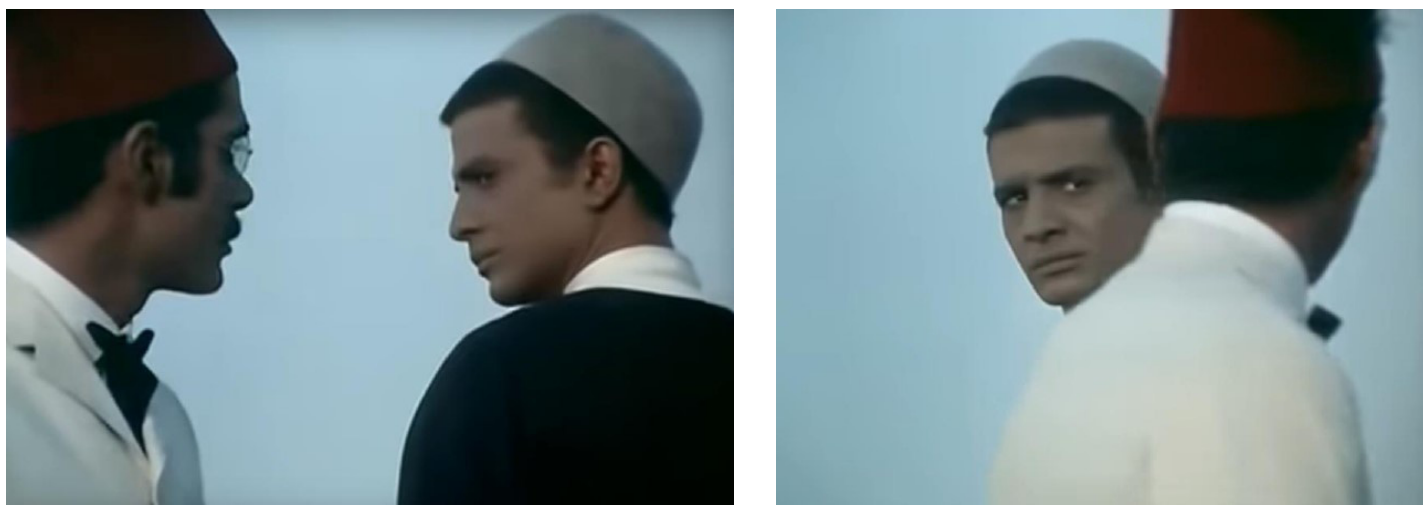

Fotogramas de La momia. Wanis y Kamal cruzan sus miradas. 
profundas contradicciones a las que se enfrentan los habitantes de esta región, especialmente Wanis. De hecho, Abdel Salam culmina esta obra lanzando una reflexión a los espectadores relativa a su decisión de desvelar la ubicación de los enterramientos. Momentos antes de que los miembros de la expedición cairota se dispongan a trasladar los sarcófagos al barco, Kamal ordena apagar las antorchas para no ser descubiertos. En un primer momento se puede pensar que se trata de una simple maniobra para esconderse de los Hurabat, pero es un acto simbólico que denota cierta falta de transparencia en la acción de sustraer los sarcófagos de su lugar de enterramiento. Se trata de evitar un mal mayor, aunque para ello sea necesario el expolio y traslado de los sarcófagos. Y con esta antítesis concluye la película, con la profunda y desasosegada mirada de Wanis al barco que se pierde por el Nilo, preguntándose a sí mismo y, de manera indirecta, al público, si ha obrado correctamente.

No solo destacan los recursos visuales, sino los sonoros, en este caso caracterizados por extensos silencios y el constante silbar del viento, un sonido particularmente característico en las zonas que conforman el Alto Egipto. Esta ausencia de diálogos aporta intensidad dramática a las escenas y favorece que el peso estético del cine de Abdel Salam recaiga en gran medida en la propia imagen.

De forma secundaria y paralela a la trama central, La momia plantea una serie de temas que entroncan directamente con la trayectoria vital y artística de Shadi Abdel Salam. Por ejemplo, el choque sociocultural entre los egipcios de la capital, los Efendis, y los del Alto Egipto, los sa'īdīs - circunstancia que el realizador de origen Sa `idi vivió de manera directa en su infancia- se ve reflejado en la tensa relación que mantienen los Hurabat con cualquier elemento que provenga del entorno urbano y amenace su forma de vida tradicional ${ }^{14}$.

Abdel Salam también aborda problemáticas relacionadas con el mundo de la compra-venta de antigüedades y la arqueología. A través de dos personajes profundamente negativos, Murad (Mohamed Nabih) y Ayyub (Shafik Noureddin), el director realiza una crítica directa y sin paliativos hacia aquellos que se lucran con el expolio del pasado. Murad y Ayyub representan el eslabón intermedio que facilita el saqueo del patrimonio, pues constituyen ese puente necesario entre el campesino pobre que se ve obligado a saquear tumbas y el comprador anónimo que las adquiere para sí mismo. Por esta razón, ambos personajes se caracterizan por sus vaivenes éticos y su actitud sibilina. Siguiendo esta línea, se atisba la voluntad del director de abrir un debate en torno al papel que juegan los arqueólogos, tanto los egipcios como los occidentales, en el expolio o la conservación del legado faraónico. John Johnston afirma que Ahmed Kamal es un personaje basado en el propio Shadi Abdel Salam, pues, desde su punto de vista, comparte con él la idea de salvaguardar el legado del antiguo Egipto y, su intérprete, Mohamed Khairi, tiene un parecido físico razonable con el joven Abdel Salam ${ }^{15}$. Siguiendo esta argumentación, podría añadirse que también les une el hecho de que, al observar las formas de vida que mantienen las sociedades egipcias rurales, ambos se percatan de la vigencia del pasado faraónico en el actual Egipto. No obstante, subyace una crítica a la labor de los arqueólogos egipcios y occidentales
[14] Ana Torres García, «Cine, historia», p. 322.

[15] John Johnston, «Rewriting History: Shadi Abdel Salam's 'The Night of Counting the Years'» en A. Dodson, J. Johnston, y W. Monkhouse (eds.), A Good Scribe and An Exceedingly Wise Man: Studies in Honour of $W J$ Tait (Londres, Golden House Publications, 2014), p. 170. 
[16] John Johnston, «Rewriting History», p. 174. en el hecho de trasladar el patrimonio cultural lejos de su lugar de origen, aunque su intención sea conservarlo y difundirlo en un lugar seguro.

Resulta evidente que esta obra se sitúa en las antípodas del cine de evasión y probablemente ese fuera uno de los motivos de su fracaso en taquilla. Tras ser proyectada desde 1969 en algunas salas de su país y festivales europeos, su reestreno en Egipto se produjo en febrero de 1975 y coincidió con la muerte de Umm Kulzum, una de las cantantes egipcias más populares. A su funeral, repleto de altos cargos del gobierno, acudieron más de cuatro millones de personas, lo que significaba que la película perdió buena parte de su público potencial ${ }^{16}$. La momia tampoco generó buenas críticas entre los arqueólogos, que consideraron que se daba una visión muy negativa de su trabajo. A pesar de las vicisitudes, este film llegó a obtener varios premios, entre ellos el premio Georges Sadoul en 1970, y, para críticos e historiadores, ha pasado a la historia como una de las muestras más sofisticadas del arte cinematográfico egipcio. Recientemente, tanto la película como la figura de Abdel Salam han sido puestos en valor a nivel internacional gracias a la labor de The World Cinema Project, un proyecto de recuperación de películas de múltiples nacionalidades liderado, entre otros, por Martin Scorsese. La restauración de La momia fue llevada a cabo en 2009 por la Filmoteca de Bolonia en colaboración con el Centro de Cine de Egipto y su coste lo financiaron Armani, Cartier, Qatar Airways, Qatar Museum y el Ministerio de Cultura de Egipto.

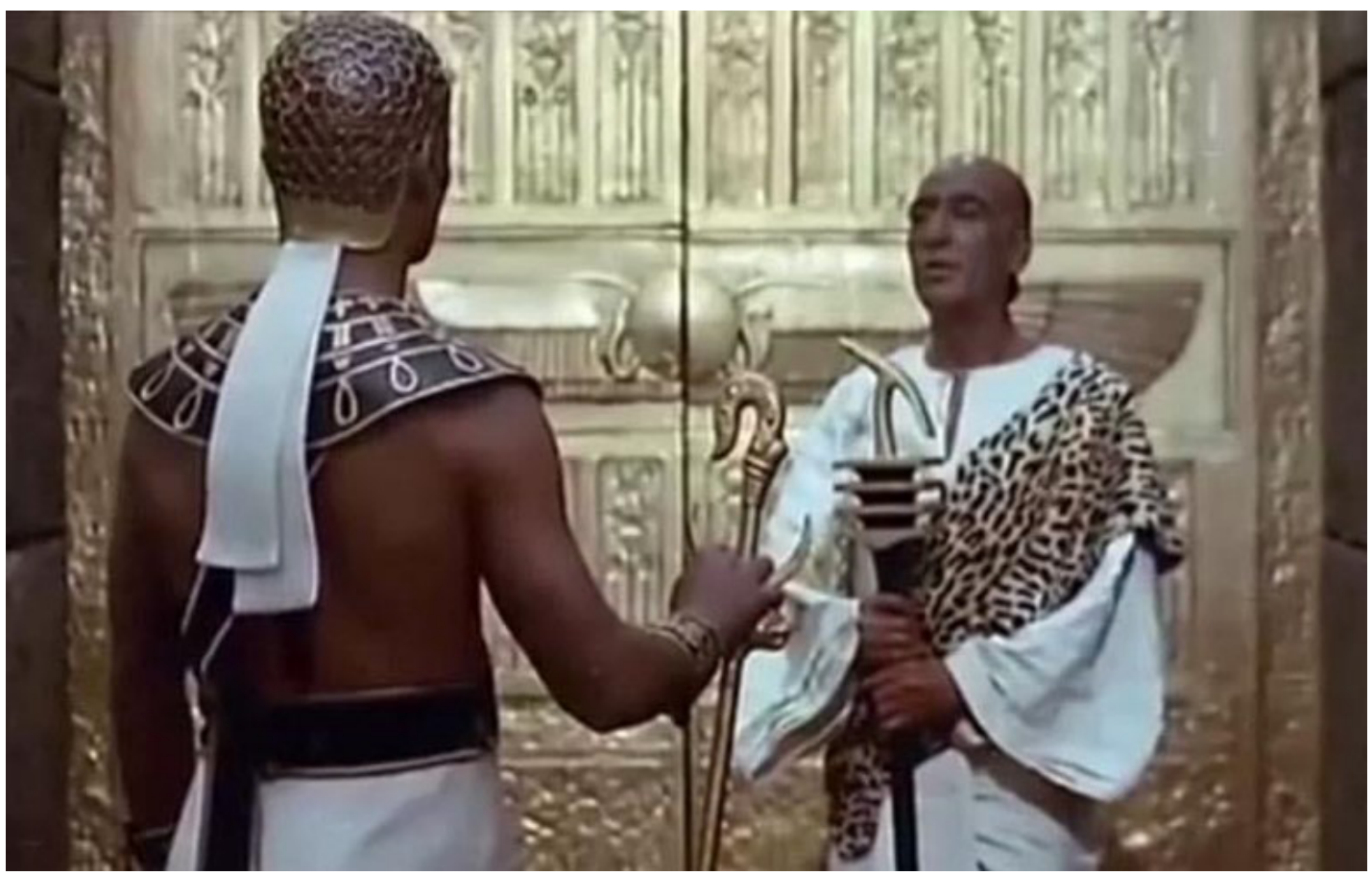

Fotograma de El campesino elocuente. 
En 1970 Abdel Salam realizó un cortometraje titulado El campesino elocuente basado en un texto homónimo del Reino Medio del antiguo Egipto datado entre los años 1970 y 1640 a.C. En la producción de este film participaron el Centro Nacional de Cine Documental y el Centro de Cine Experimental, cuyo jefe era el propio Abdel Salam desde 1968. Ambos centros formaban parte de la Organización General del Cine, que dependía directamente del Ministerio de Cultura.

El cortometraje relata la historia de un humilde campesino que sufre un robo a mano de tres ladrones liderados por un oficial de rango menor. El campesino acude al encuentro de Rensi, gobernador del territorio, en busca de justicia, pero le es denegada. Sin embargo, tras varias audiencias y haciendo uso de una retórica excelsa, el campesino logra que se imparta justicia mediante la restitución de sus pertenencias.

En solo veinte minutos de metraje, el director egipcio muestra un gran despliegue de recursos técnicos que favorecen la veracidad de las imágenes. Junto con Faraón, El campesino elocuente es una de las producciones que representa el antiguo Egipto con mayor rigor histórico. A través del contacto entre el campesino y el resto de personajes del film, Abdel Salam es capaz de trasmitir la idea de una sociedad fuertemente jerarquizada, en la que probablemente las relaciones entre el pueblo llano y la élite funcionarial del Estado funcionasen con estas fórmulas de sumisión. Hay varias escenas caracterizadas por emplear una serie de encuadres, asociaciones de planos, gestos y posturas que trasladan la imaginación de los espectadores al Egipto faraónico. Así, el cortometraje arranca con dos secuencias contrapuestas. En primer lugar, aparecen los títulos de crédito proyectados sobre una pintura mural del antiguo Egipto de una escena agrícola que, inmediatamente después, da paso a un plano del campesino tirando de dos burros. Dicho plano se va ampliando paulatinamente hasta formar tres siluetas recortadas sobre la claridad de la arena del desierto, reflejando de manera evidente una similitud entre el arte parietal egipcio y la composición de planos cinematográficos. Otro gran logro en cuanto al verismo de la ambientación histórica es la relación entre el campesino y Rensi, especialmente la primera vez que se encuentran. El campesino no habla directamente con el gobernador, sino con uno de los miembros de su séquito. Posteriormente, cuando se dirige directamente a él para reclamar justicia, lo hace de rodillas y sin establecer contacto visual directo, en una posición totalmente sumisa. Ahmed Marei encarna al personaje del campesino elocuente y su interpretación, comedida y caracterizada por sus intensas miradas, vuelve a ser fundamental para transmitir la solemnidad y el hieratismo que reflejan los monumentos del Egipto faraónico.

Shadi Abdel Salam plantea una adaptación audiovisual de una obra egipcia preislámica, lo cual tiene implicaciones culturales e ideológicas fundamentales. Se trata de poner en valor la literatura del antiguo Egipto y demostrar 
[17] Para un análisis exhaustivo de las fuentes literarias que utilizó Abdel Salam, véase Allen Douglas y Fedwa Malti-Douglas, «Film and Pharaonism: Shadi 'Abd al-Salam's Eloquent Peasant» en Issa Boullata y Terri Deyoung, Tradition \& Modernity in Arabic Literature. (Arkansas, University of Arkansas Press, 1997), pp. 193-205. que, al igual que la creación literaria en lengua árabe, la literatura faraónica es digna de ser reinterpretada en disciplinas artísticas modernas, en este caso en el cine. Del mismo modo que hizo en La momia, utiliza el árabe clásico para los diálogos, los cuales están inspirados tanto en el texto clásico del Reino Medio como en diversas adaptaciones y reinterpretaciones que han sido llevadas a cabo con posterioridad ${ }^{17}$.

Además, como es habitual en su obra, el alejandrino propone un ejercicio de recuperación del pasado faraónico para la memoria histórica colectiva de Egipto. Abdel Salam utiliza el antiguo Egipto como marco para introducir dos conceptos que tienen vigencia en el Egipto contemporáneo: la justicia y la creación artística. La justicia es el tema central del cortometraje y, su búsqueda incansable por parte del campesino es lo que condiciona el devenir de la trama. Abdel Salam introduce la idea de que la base histórica común entre el antiguo Egipto y el contemporáneo reside en la existencia y aplicación rigurosa de la justicia, es decir, que la sociedad egipcia de tradición islámica y la antigua civilización egipcia comparten un ideal común de justicia y, por lo tanto, una es heredera directa de la otra. En lo que a la creación artística se refiere, el film desprende un aire de reivindicación de la cultura y del arte "periféricos», es decir, no occidentales. El realizador egipcio ofrece una adaptación en árabe clásico de un texto de la Antigüedad, puramente africano y plasmado desde una óptica cinematográfica de tradición árabe. Todo el proyecto está financiado mediante capital egipcio, una maniobra muy eficaz de cara a mantener su independencia creativa y no caer bajo las influencias o, en el peor de los casos, imposiciones de modelos de producción audiovisual occidentales. La creación artística fundamental a la que hace referencia directa El campesino elocuente es la palabra. De hecho, la capacidad retórica del campesino es lo que despierta el interés de Rensi y, a la postre, lo que le lleva a dictar sentencia en su favor. La superioridad retórica del humilde aldeano se ve reforzada por los extensos silencios del gobernador, un recurso que transmite de forma velada la idea de que la justicia, si bien la imparten personas de una clase social privilegiada y con legitimidad político-religiosa, es un concepto universal que no se desvanece en el tiempo.

La ausencia de datos hace que resulte complicado conocer con certeza la acogida comercial que pudo tener este cortometraje, aunque, si tenemos en cuenta el tipo cine que propone Shadi Abdel Salam, lo más probable es que el rendimiento económico de la cinta fuese escaso. Sin embargo, obtuvo una serie de premios a nivel europeo, entre ellos el Lábaro de Oro en la Semana Internacional de Cine de Valladolid (SEMINCI) de 1971. Lo que resulta incuestionable es el valor artístico de esta producción, no solo por la rareza de su ambientación dentro de la cinematografía egipcia, sino por la voluntad de Abdel Salam de sentar las bases de un cine nacional propio, basado en unos códigos de representación diferenciados de otros países. Al igual que La momia, esta cinta fue restaurada como parte de The World Cinema Project e intervinieron las mismas instituciones tanto en su restauración como en su financiación. 
Ya en la década de los setenta, Shadi Abdel Salam realiza dos documentales ambientados en el Egipto contemporáneo en los que continúa reflexionando sobre la identidad egipcia y su bagaje histórico-cultural.

En primer lugar, hablemos de Horizontes (1973). Este documental transmite alguno de los principales aspectos de la idiosincrasia de la sociedad egipcia como resultado de una extensa trayectoria artística y religiosa. Para ello, Abdel Salam muestra una sucesión de manifestaciones culturales propias de su país, desde la arquitectura egipcia más emblemática, como las pirámides, hasta pinturas de artistas pertenecientes a corrientes artísticas contemporáneas, como la abstracción. También introduce secuencias en las que refleja actividades propias de la antropología y la etnografía, como labores de orfebrería, manufacturas textiles o el trabajo del cuero.

Uno de los recursos más llamativos es la ausencia de narrador, un hecho que entronca directamente con el estilo cinematográfico que había mostrado en sus dos producciones de ficción previas: La momia y El campesino elocuente. En ambas se traslada parte del peso narrativo a las imágenes y se otorga mucha importancia a los largos silencios de los personajes. Al tratarse de un documental, estas técnicas fílmicas se reproducen con mayor claridad en Horizontes, pues la propia imagen habla por sí misma sin necesidad de ser explicada.

Abdel Salam dota de mayor verismo a este documental mediante la filmación de las imágenes con la cámara al hombro, dando lugar a movimientos de cámara que se asemejan a la mirada humana. Además, rompe cualquier idea de ficción mostrando la propia cámara y al equipo de rodaje, a quienes hace protagonistas del documental. De hecho, el film concluye con los miembros del rodaje marchándose en su furgoneta y dejando un plano general y fijo del desierto.

Aunque se trata de una producción que aborda aspectos del Egipto contemporáneo, el realizador introduce una breve referencia a la importancia de la recuperación del pasado faraónico, en este caso a través de la educación. En un momento dado se proyecta una imagen fija de la silueta de la pirámide de Kefrén, se corta el plano y, a continuación, nos muestra una escena en un colegio. Esta imagen se funde y pasamos a ver una escena en un centro de educación superior.

Por su parte, Ejércitos del sol (1975) resulta menos determinante en su relación con la recuperación histórica del antiguo Egipto, que en este documental es inexistente. Abdel Salam presenta imágenes reales de la Guerra de Yom Kipur, que tuvo lugar entre el 6 y el 25 de octubre de 1973, intercaladas con declaraciones de los propios soldados. Todo esto, como ocurría en Horizontes, sin necesidad de una voz en off que narre lo que sucede. Este documental resulta interesante por la voluntad de recuperar la moral de los egipcios, hundidos anímicamente como consecuencia de las sucesivas derrotas militares que sufrieron ante Israel. 
3.2.4. El pasado faraónico a través del documental. La trilogía de la educación: El trono de oro de Tutankamón, Detrás de las pirámides y A propósito de Ramsés II.

Estos tres documentales realizados en los años ochenta pertenecen a la denominada «trilogía de la educación $»^{18}$. En ellos se aborda de forma directa el peso del pasado faraónico en el Egipto contemporáneo y la importancia de recuperar su memoria a través de la educación infantil y superior. Nos encontramos ante producciones de corte documental que utilizan historias ficticias como base narrativa. No ha sido posible realizar los visionados de Detrás de las pirámides (1984) y A propósito de Ramsés II (1986), por lo que solo se hará referencia a El trono de oro de Tutankamón (1982).

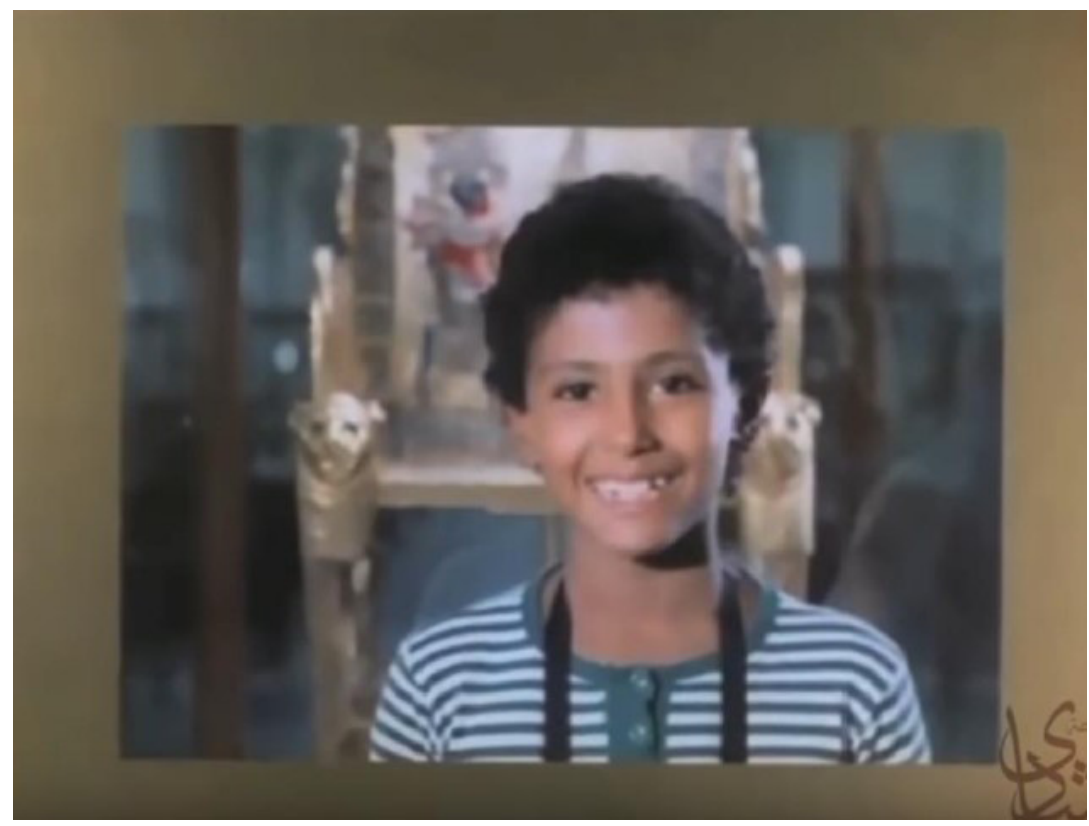

Fotograma de El trono de oro de Tutankamón (Korssy Tout Ankh Amun Al Zahaby, Shadi Abdel Salam, 1982).

[18] Allen Douglas y Fedwa Malti-Douglas, «Film and Pharaonism», p. 194.
El trono de oro de Tutankamón fue producido por la Organización Egipcia de Antigüedades, por lo que su vinculación con la conservación del patrimonio faraónico y su difusión educativa es absoluta. A través de la relación entre Mohamed, un joven conservador del Museo Egipcio del Cairo, y su sobrino pequeño, fascinado por las antigüedades egipcias, Abdel Salam documenta la restauración del trono de Tutankamón. Esta obra se articula en torno a dos ideas: las labores de conservación y restauración del patrimonio histórico egipcio, por un lado, y la importancia de su difusión educativa por otro. 
Durante todo el documental están presentes las labores de restauración de los objetos del antiguo Egipto, así como los profesionales encargados de llevarlas a cabo. Se trata, en gran medida, de una obra audiovisual de propaganda del trabajo desarrollado por el Ministerio de Antigüedades de Egipto, ya que hace especial hincapié en mostrar el rigor científico de los conservadores del museo. También es una forma de recalcar la importancia de salvaguardar el patrimonio antiguo, empleando todos los recursos económicos y humanos que sean posibles. El cénit de este mensaje se produce al final del documental, en el momento en que el trono está restaurado y listo para ser expuesto en las salas del museo. Un plano cenital muestra al séquito que traslada y acompaña el trono, formado por operarios del museo y autoridades policiales, prácticamente emulando una marcha marcial. A continuación, la cámara se sitúa tras las vitrinas del museo y, mediante un travelling paralelo, acompaña el traslado de la pieza hasta su instalación en la vitrina. Una vez sellada, constituye una de las obras más importantes del museo como reflejo del esplendor de la cultura material del Egipto faraónico.

En cuanto a la intencionalidad educativa de El trono de oro de Tutankamón, uno de los recursos de mayor interés es la relación que se establece entre los diferentes procesos de restauración de la pieza y las etapas de aprendizaje del niño, además del vínculo que se va forjando entre este y el joven faraón. En una escena del documental, se contraponen dos primeros planos, el primero de la máscara mortuoria de Tutankamón, seguido del rostro de niño sonriendo al observar esta icónica obra de arte. Las referencias a la necesidad de recuperar el legado histórico del antiguo Egipto a través de la educación y la difusión son constantes. De esta forma, observamos que Mohamed transmite a su sobrino sus conocimientos sobre las diferentes dinastías. A su vez, el niño comunica a sus amigos todo lo que ha aprendido sobre la colección del museo, generando una cadena de difusión esencial a la hora de poner en valor el legado de esta civilización. Siguiendo esta línea, también se advierte una cierta reivindicación del museo como institución encargada de conservar, restaurar, exhibir y difundir el patrimonio cultural de la etapa faraónica.

\subsubsection{Un gran proyecto inconcluso: Akhenatón}

En un coloquio sobre cinematografía y poesía celebrado en Bilbao, Nekane Zubiaur comentaba con José Julián Bakedano, director de cine experimental y Director de la Cinemateca de Bilbao, la importancia que tienen los proyectos no realizados a la hora de estudiar la trayectoria de un director ${ }^{19}$. Esta circunstancia se da en este proyecto fallido, pues su voluntad de llevar a cabo Akhenatón muestra tres elementos que ejemplifican cómo entendía el cine Abdel Salam.

En primer lugar, como es habitual en casi toda su obra, la ambientación de esta película se sitúa en el antiguo Egipto para narrar la vida de Akhenatón, uno de los faraones más peculiares de la historia por su controvertida re-
[19] En el marco de una investigación sobre la trayectoria de la Cinemateca, tuve la oportunidad de entrevistar a José Julián Bakedano y estuvimos rememorando un coloquio en la Biblioteca Municipal de Bidebarrieta (Bilbao) en el que él hablaba de sus proyectos que no llegaron a materializarse. Coloquio disponible en: $<$ https://www.youtube.com/ watch?v= rBu_MHA_DBo> (14/10/2019). 
[20] Domingo Sola, «El mundo de Shadi Abdel Salam» (Latente. Revista de Historia y Estética del Audiovisual, $\mathrm{n}^{\circ} 3,2005$ ), p. 137 .

forma religiosa. Además, la intención de representar este pasado y adoptarlo como parte intrínseca de la historia egipcia se ve reforzada por el método de financiación que escogió para esta película. Para Abdel Salam solo era posible producir este largometraje mediante capital exclusivamente egipcio, razón por la cual estuvo más de una década en busca de financiación, aunque sin mucho éxito. Es más, el proyecto no llegó a realizarse principalmente por la falta de interés del gobierno egipcio y de los productores. Este hecho muestra otra característica del pensamiento cinematográfico del director alejandrino: sentar las bases de un cine nacional egipcio, empezando por su producción. Por último, gracias a la exposición permanente que se ha instalado en la Biblioteca de Alejandría, que incluye los bocetos que Abdel Salam realizó para Akhenatón, se puede corroborar su minucioso trabajo en los diseños decorativos y de vestuario, caracterizados por el gran rigor histórico.

Es imposible conocer el resultado final de esta producción, pero, tomando las palabras de Domingo Sola Antequera, se puede intuir un esbozo: «[...] su compromiso ético hubiera supuesto la presentación de un antihéroe sumido en una crisis existencial en medio de un situación política y social complicada, asfixiante, $[\ldots] »^{20}$.

\section{Conclusiones}

Es evidente que la filmografía de Shadi Abdel Salam es escasa, un hecho que se debe a diversas razones. Ante todo, es consecuencia del alto nivel de autoexigencia que se marcaba a sí mismo, como prueba el tiempo que empleaba en confeccionar sus

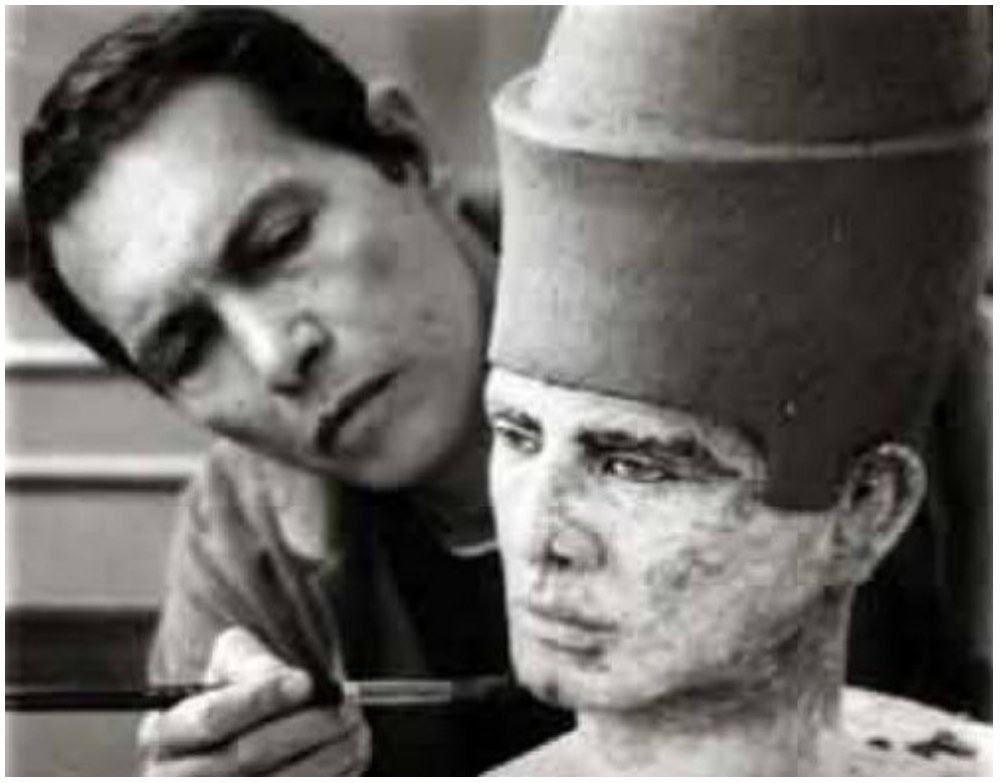

Shadi Abdel Salam trabajando en los bocetos para Akhenatón (Ikhnâtoun, inconclusa). películas. Como se acaba de indicar, llegó a trabajar durante una década en la producción de Akhenatón. Además, su cine se situaba en las antípodas del cine de evasión egipcio y no gozaba del favor del público mayoritario. Sus películas no obtuvieron grandes beneficios económicos, por lo que siempre estuvo en una situación de dependencia respecto del Estado para financiar sus proyectos.

Sin embargo, Shadi Abdel Salam se ha convertido en uno de los autores más reconocidos por la historio- 
grafía y la crítica cinematográfica egipcia e internacional, así como una influencia fundamental para realizadores y diseñadores árabes en general y egipcios en particular. La importancia de su figura dentro de la cinematografía egipcia se debe, por un lado, a su voluntad de realizar películas con un marcado componente artístico, donde el aspecto visual del film esté dotado de elementos que permitan la satisfacción estética del espectador. Por otro lado, constituyendo una característica invariable a lo largo de toda su obra, destacan sus esfuerzos por incorporar la historia del antiguo Egipto a la memoria histórica desde una perspectiva educativa, tal y como él mismo expresó:

Quiero mostrarme y mostrar Egipto. Trato de configurar un cine egipcio volviendo a las bellas artes faraónicas. [...] Mi intención es mostrar la personalidad del egipcio moderno que recupera sus orígenes históricos $[\ldots]^{21}$.

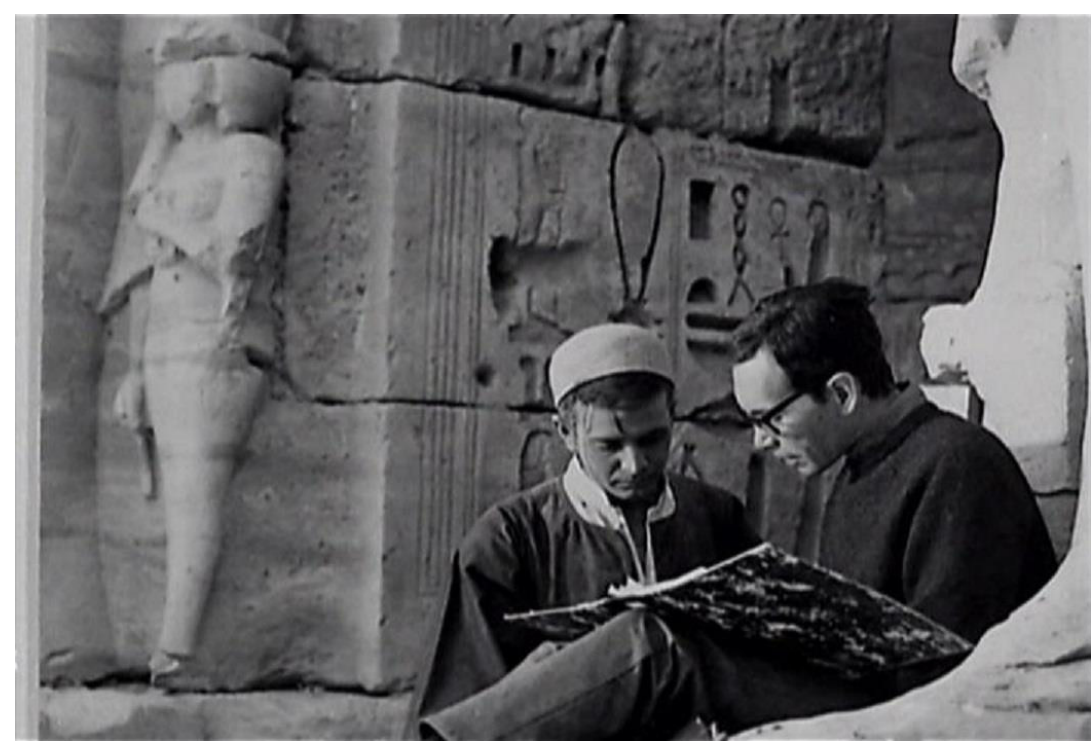

Shadi Abdel Salam y Ahmed Marei durante el rodaje de La momia.

\section{Bibliografía}

Abdel Salam, Salam, «Entrevista» (Gomhuria Magazine, 16 de diciembre de 1969). Disponible en: <http://www.luxorafricanfilmfestival.com/en/PastEditions/2014/ TributeDedication/Shadi\%20Abdel\%20Salam> (01/03/2020).

Douglas, Allen y Malti-Douglas, Fedwa, «Film and Pharaonism: Shadi 'Abd al-Salam's Eloquent Peasant», en Issa Boullata y Terri Deyoung (eds.), Tradition \& Modernity in Arabic Literature (Arkansas, University of Arkansas Press, 1997), pp. 193-205.

ELENA, Alberto, «Elementos para una historia del cine en el mundo árabe», en Los cines periféricos: África, Oriente Medio, India (Barcelona, Paidós, 1999).
[21] Shadi Abdel Salam, «Entrevista». (La traducción es nuestra). 
García Moreno, Sol, «Un consorcio de centros europeos como el Louvre o el British renovará el Museo Egipcio de El Cairo», (ARS Magazine, 2019). Disponible en: $<$ https://arsmagazine.com/un-consorcio-de-centros-europeos-como-el-louvre-oel-british-renovara-el-museo-egipcio-de-el-cairo/> (16/05/2019).

Johnston, John, «Rewriting History: Shadi Abdel Salam's 'The Night of Counting the Years'», en A. Dodson et al., A Good Scribe and An Exceedingly Wise Man: Studies in Honour of W J Tait., 2013 (Londres, Golden House Publications, 2014), pp. 168-176.

Molinero Polo, Miguel Ángel, «La momia de Shadi Abdel-Salam y la arqueología colonial», en Miguel Ángel Molinero y Domingo Sola (coord.), Arte y sociedad del antiguo Egipto (Madrid, Zugarto, 2000), pp. 273-283.

SÁnchez CASAdo, Raúl, «Ritual egipcio y cine: la representación cinematográfica de la práctica cultural del antiguo Egipto», en Francisco Salvador Ventura (ed.), Cine e Historia (s). Maneras de relatar el pasado con imágenes (París, Université ParisSud, 2015), pp. 117-132.

SCORSESE, Martin, World Cinema Project, 2009. Disponible en: <http://www.film-foundation.org/world-cinema> (18/09/2019).

SHAFiк, Viola, «Egyptian Cinema», en Oliver Leaman Companion Encyclopedia of Middle Eastern and North African Film (Londres/Nueva York, Routledge, 2001), pp. 23-130.

Sola Antequera, Domingo, «El mundo de Shadi Abdel Salam» (Latente. Revista de Historia y Estética del Audiovisual, n. ${ }^{\circ}$ 3, 2005), pp. 133-142.

Torres García, Ana, «Cine, historia e identidad nacional: La Momia de Šādī 'Abd alSalām» (Miscelánea de estudios árabes y hebraicos. Sección Árabe-Islam, n. ${ }^{0}$ 51, 2002), pp. 315-326.

Aceptado para revisión por pares: 28 de enero de 2020

Aceptado para publicación: 26 de marzo de 2020 
